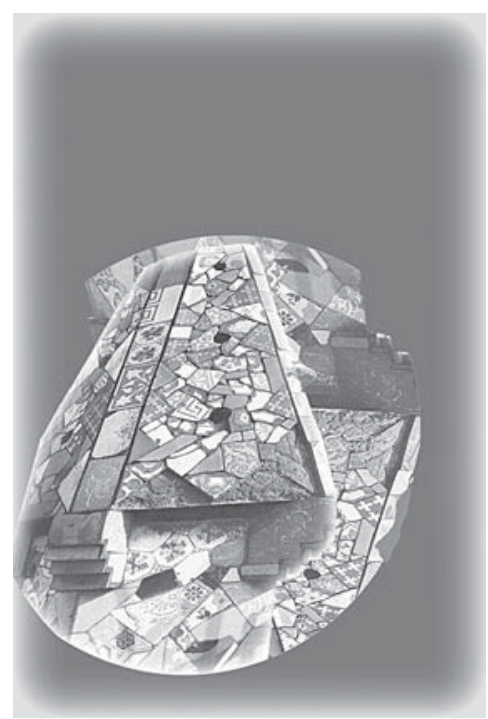




\title{
COMPLEXIDADE E DIALÉTICA: CONTRIBUIÇŐES À PRÁXIS POLÍTICA E EMANCIPATÓRIA EM EDUCAÇÃO AMBIENTAL
}

\author{
Carlos Frederico Bernardo Loureiro*
}

\begin{abstract}
RESUMO: No presente artigo analisa-se as principais orientaçôes teórico-metodológicas que constituem a Educação Ambiental, à luz de um referencial inserido na tradição crítica e dialética histórica. Problematizam-se as formulaçôes funcionalistas e organicistas produzidas no campo da teoria dos sistemas e da visão holística que diluem os aspectos políticos, sociais e culturais inerentes à complexidade ambiental, estabelecem uma unidade abstrata entre sociedade e natureza e, em algumas de suas propostas, hipostasiam o todo em relação às partes. Ao final, são resgatadas categorias definidoras da vertente emancipatória ou transformadora da Educação Ambiental, relevantes para um fazer educativo ambientalista que enfatize a participação cidadã, a ressignificação do ambiente e a transformação societária, enquanto princípios estruturantes e indissociáveis do processo de requalificação do humano na natureza.
\end{abstract}

Palavras-Chave: Educação Ambiental. Práxis. Emancipação. Transformação social. Complexidade.

COMPLEXITY AND DIALECTIC: CONTRIBUTIONS TO THE POLITICAL AND EMANCIPATORY PRAXIS IN ENVIRONMENTAL EDUCATION

ABSTRACT: This paper analyses the main theoretical and methodological approaches to environmental education from a critical perspective within the historical dialectics. It problematizes the functional and organic formulations, produced in the field of theory of systems, and the holistic vision that dilute the political, social and cultural aspects inherent to the environmental complexity, establish an abstract unity among nature and society and, in some of its

* Doutor em Serviço Social pela Universidade Federal do Rio de Janeiro (UFRJ) e professor adjunto da Faculdade de Educação da mesma Universidade.E-mail: floureiro@openlink.com.br.

Educ. Soc., Campinas, vol. 26, n. 93, p. 1473-1494, Set./Dez. 2005 
propositions, segregate the whole in relation to the parts. In the end, the relevant categories that define the emancipatory or transformative views of environmental education are brought forward in an approach that emphasizes citizenship participation, the re-signification of the environment, and the social transformation as structuring principles bound to the process of re-qualification of the human in the nature.

Key words: Environmental Education. Praxis. Emancipation. Social transformation. Complexity.

\section{Introdução}

A

Educação Ambiental integra propostas educativas oriundas de concepções teóricas e matrizes ideológicas distintas, sendo reconhecida publicamente, no Brasil, como de inegável relevância para a construção de uma perspectiva ambientalista de mundo e de sociedade. Tal fato é relativamente simples de compreender quando a pensamos como uma práxis educativa que se constitui no próprio processo de atuação, nas diferentes esferas da vida, das forças sociais identificadas com a "questão ambiental". Estas, em suas múltiplas tendências, nas últimas três décadas, procuram materializar açôes distintas e por vezes antagônicas, almejando alcançar patamares societários construídos por meio de caminhos vistos como sustentáveis, requalificando a compreensão e o modo de nos relacionarmos na natureza.

No Brasil, as discussões afetas à Educação Ambiental adquirem caráter público abrangente em meados da década de 1980, com a realização dos primeiros encontros nacionais, a atuação crescente das ONGs ambientalistas e movimentos sociais que incorporaram a temática em suas lutas, e a ampliação da produção acadêmica específica (Loureiro et al, 2002). Sua importância para o debate educacional se explicita formalmente na obrigatoriedade constitucional, em sua inclusão nos Parâmetros Curriculares Nacionais e na publicação da Lei Federal que define a Política Nacional de Educação Ambiental (Lei 9795/1999), instrumentos legais e documentos governamentais que asseguram à temática um caráter transversal, indispensável e indissociável da política educacional brasileira - mesmo que possamos considerar que a Educação Ambiental não esteja consolidada nacionalmente enquanto política pública (Loureiro, 2004). 
Desde a década de 1970, quando identificamos as primeiras experiências denominadas de Educação Ambiental, dois grandes blocos político-pedagógicos começaram a se definir e disputar hegemonia no campo das formulações teóricas, na Academia, nas articulações internas às redes de educadores ambientais e na definição da Política Nacional, com vertentes internas e interfaces complexas e diferenciadas. Cabe destacar que não estamos afirmando que somente existam esses dois blocos, pois poderíamos lembrar de experiências e pensadores que não se enquadram estritamente e que apresentam proximidades ou não com eles de acordo com suas orientações específicas. Mas buscamos explicitar os macroeixos norteadores que historicamente alcançaram maior destaque no cenário da Educação Ambiental, seja pela proximidade com as discussóes políticas da área, pela tradição na educação ou pela afinidade com teorias que obtiveram maior acúmulo no debate ambientalista.

Feito esse esclarecimento e utilizando-nos de sistematização feita por Lima (2002) e de elementos por nós anteriormente indicados (Loureiro, 2003b e 2004), podemos assim classificar os dois blocos em suas ênfases. Um denominado conservador ou comportamentalista, cujas características centrais são:

- compreensão naturalista e conservacionista da crise ambiental;

- educação entendida em sua dimensão individual, baseada em vivências práticas;

- despolitização do fazer educativo ambiental, apoiando-se em pedagogias comportamentalistas ou alternativas de cunho místico;

- baixa problematização da realidade e pouca ênfase em processos históricos;

- foco na redução do consumo de bens naturais, descolando essa discussão do modo de produção que a define e situa;

- diluição da dimensão social na natural, faltando entendimento dialético da relação sociedade-natureza (sociedade enquanto realização coletiva e objetivada da natureza humana, ou melhor, enquanto realização e exigência para a sobrevivência da espécie humana - Morin, 2002a);

- responsabilização pela degradação posta em um homem genérico, fora da história, descontextualizado social e politicamente. 
Complexidade e dialética: contribuições à práxis política e emancipatória...

E outro chamado de transformador, crítico ou emancipatório, cujas características mais comuns são:

- busca da realização da autonomia e liberdades humanas em sociedade, redefinindo o modo como nos relacionamos com a nossa espécie, com as demais espécies e com o planeta;

- politização e publicização da problemática ambiental em sua complexidade;

- convicção de que a participação social e o exercício da cidadania são práticas indissociáveis da Educação Ambiental;

- preocupação concreta em estimular o debate e o diálogo entre ciências e cultura popular, redefinindo objetos de estudo e saberes;

- indissociação no entendimento de processos como: produção e consumo; ética, tecnologia e contexto socio-histórico; interesses privados e interesses públicos;

- busca de ruptura e transformação dos valores e práticas sociais contrários ao bem-estar público, à eqüidade e à solidariedade.

Tais blocos dinâmicos, além de serem influenciados por concepções pedagógicas distintas, fundadas sob modos específicos de se entender a educação e suas finalidades sociais, definiram-se, no que se refere à compreensão de mundo e sociedade, a partir da apropriação de dois métodos que, independentemente da "questão ambiental" ser um objeto de interesse direto ou não, se estruturaram em cima de categorias centrais para a perspectiva ambientalista (integração, totalidade, processos, movimento, relações, entre outras). Em termos gerais, o primeiro bloco mencionado está fortemente influenciado pela Teoria dos Sistemas Vivos, pela Teoria Geral dos Sistemas, pela visão holística, pela Cibernética e pelo pragmatismo ambientalista da proposta de "alfabetização ambiental" norte-americana. E o segundo, mais inserido nos debates clássicos do campo da educação propriamente dita, pela dialética em suas diferentes formulações de orientação marxista ou em diálogo direto com esta.

Contudo, devemos alertar para o fato de que tal uso não se deu de modo estanque e sem a busca de interlocuções e diálogos, por vezes proveitosos, por vezes equivocados. Para exemplificar o que estamos dizendo, no campo do "diálogo profícuo" lembramos que há autores de reconhe- 
cido e notório saber que procuraram estabelecer novas sínteses entre esses métodos, dos quais se destacam Edgard Morin (reunindo a dialética em Heráclito, Hegel e Marx, Teoria dos Sistemas, Teoria da Informação e Cibernética, para sistematizar a Teoria da Complexidade) e Enrique Leff (reunindo Teoria da Complexidade, hermenêutica e dialética marxista). No que se refere às apropriações indevidas de categorias conceituais de pensamentos contrários no modo de entender o mundo e as finalidades da educação, encontramos, não raramente, educadores ambientais que realizam suas ações no campo de uma pedagogia conservadora, do pragmatismo ambientalista norte-americano e sob abordagens ecológicas sistêmicas funcionalistas e organicistas, utilizando-se discursivamente de autores críticos como Moacir Gadotti e Paulo Freire, sem dialetizar e discernir o que há de contribuição possível e recíproca e o que é absolutamente incongruente (Loureiro, 2004).

Consideraçōes iniciais feitas, é oportuno analisar as formulações sistêmicas clássicas e a matriz holística normalmente a esta associada, pela recorrência entre educadores ambientalistas, à luz de uma abordagem dialética histórica em permanente diálogo com a Teoria da Complexidade e focada no sentido educativo das práticas em Educação Ambiental. Com isso, pretendemos problematizar categorias conceituais estruturantes e explicitar as implicações político-pedagógicas da incorporação pouco reflexiva dessas visões sociais de mundo significativas para a Educação Ambiental, indicando, ao final, conceitos relevantes para o entendimento de sua vertente emancipatória ou transformadora, inspirada primordialmente na pedagogia freireana e, de modo menos direto, em autores que no campo da educação conformaram as pedagogias críticas.

\section{Problematizando as orientações teórico-metodológicas da Educação Ambiental}

Não é incomum se falar dentro do jargão ambientalista de visão sistêmica em sentido amplo, incluindo aí perspectivas dos mais diferentes tipos, posto que um sistema pode ser definido como um conjunto de partes coordenadas entre si, cujas leis ordenam os fenômenos que são vistos prioritariamente como fluxos e processos, ou no dizer de Bertalanffy (1977), como um conjunto de unidades em inter-relações mútuas. Assim, desde o próprio pensamento dialético hegeliano ou marxista até a cibernética e a robótica, passando pelas filosofias orien- 
Complexidade e dialética: contribuições à práxis política e emancipatória...

tais, o funcionalismo, o organicismo e o holismo, todos literalmente cabem no rótulo de serem formulações sistêmicas. No entanto, essa "bondosa” generalidade conceitual complica mais do que facilita o entendimento do que fundamenta a Educação Ambiental. A Teoria da Complexidade em Morin, a dialética marxista e o holismo não compartilham da mesma epistemologia (Petraglia, 2001). Particularmente ao confrontarmos as duas primeiras em relação à terceira verificamos construçôes distintas no que se refere aos conceitos de totalidade, de compreensão da relação parte-todo e de educação. Assim, sem ignorar o fato de que a visão sistêmica vem sendo incorporada por diferentes ciências, adquirindo significados próprios, aqui, para efeito de análise, vamos nos referir a esta, a seguir, em sentido estrito. Aos seus fundamentos consolidados em meados do século XX, quando tal denominação ganhou aceitação nos meios acadêmicos, científicos e filosóficos, tendo por base a Teoria Geral dos Sistemas e os modelos clássicos oriundos da física, da biologia e da sociologia funcionalista.

Ao pensarmos a educação, enquanto práxis social cujo fim é o aprimoramento humano naquilo que pode ser aprendido e recriado a partir dos diferentes saberes existentes em uma cultura, de acordo com as necessidades, possibilidades e exigências de uma sociedade, alguns problemas se explicitam no uso de abordagens sistêmicas.

O primeiro e principal é a leitura direta dos fenômenos sociais fundamentada em modelos matriciais de retroação alimentados por elos de feedback, relativizando-se ou ignorando-se que o ambiente é também produto do trabalho e da práxis humana. Tal leitura ocasiona um grau de incerteza e mutabilidade e de ação intencional para além da previsibilidade de qualquer modelo, por mais dinâmico e relacional que este consiga ser. Uma coisa é alimentação e retroalimentação, outra bem distinta é intervenção e criação consciente pela ação mediada culturalmente. Formular um pensamento sistêmico em cima de fluxos energéticos, materiais e termodinâmico, enfatiza adequadamente os organismos vivos, mas dissolve a existência, a cultura e demais fenômenos tipicamente humanos.

Para Floriani e Knechtel (2003), as visões sistêmico-holísticas e o sistemismo formal contribuem efetivamente para a emergência de paradigmas que procuram relacionar sistemas sociais e sistemas naturais estrito senso, em construções interdisciplinares baseadas no conceito de autopoiese. Contudo, como destacam os referidos autores, nesse movimento recaem na perigosa certeza de se ter alcançado o "modelo do mo- 
delo" ou o "método unificador" de todas as ciências e saberes, sintetizando em matrizes sistêmicas os processos materiais e mentais das sociedades humanas e da vida. Acabam, assim, por reproduzir o equívoco do positivismo e de algumas correntes marxistas que consideravam, cada um a seu modo e à sua época, haverem descoberto o único método capaz de apontar a verdade. Considerando o ambiente enquanto "complexidade do mundo" (Leff, 2001, p. 17), não há um único método válido, mas métodos que, ao trabalharem com a perspectiva da totalidade, podem e devem dialogar entre si, reconhecendo as especificidades de cada ciência e de outros métodos, num processo aberto que permita a redefiniçẫo dos objetos de cada ciência e recortes da materialidade da vida (Leff, 2003).

Além disso, segundo Morin (2003), apesar de Bertalanffy (op. cit.) proclamar a possibilidade do conflito em um sistema, não desenvolve esta importante noção. Como resultado desse tipo de formulação, o sistema vira sinônimo de harmonia, funcionalidade, síntese superior que comanda as partes; algo incapaz de ser pensado em suas contradições, sem as quais não existem organização e transformação. Essa simplificação se dá prioritariamente por duas premissas não necessariamente consonantes. Uma primeira em que o conflito e o antagonismo são reduzidos ao sentido de diversidade natural, previsíveis na dinâmica sistêmica, e não entendidos como constituintes da desordem na organização da vida e das estruturas históricas e sociais que formam a realidade complexa. E outra, em que o conflito é visto como uma fragilidade, uma incorreção a ser superada quando o ser humano atingir seu estado integral, ou seja, harmônico, numa concepção similar ao positivismo de Augusto Comte e ao evolucionismo spenceriano.

Um outro aspecto, a ser considerado dentro das pretensões de um artigo, decorre de uma possibilidade de raciocínio lógico-formal. Um sistema dinâmico procura sempre se recompor e readequar às relações de modo a funcionar plenamente e em equilíbrio, e isso é válido para sistemas ecológicos ou sociais. Caso desconsidere-se, nesse ponto em particular, a especificidade histórica humana, pode-se recair no funcionalismo organicista, em que as mudanças se dáo para o bom funcionamento do sistema (em termos de sociedade contemporânea, do capitalismo). A conclusão é inevitável: o que pode ser feito com a sociedade é torná-la ambientalmente sustentável e não superá-la. E isso acarreta uma visão sistêmica politicamente conservadora e reformista, em que a educação aí se inscreve para cumprir a função social de fazer as pessoas se adaptarem 
Complexidade e dialética: contribuições à práxis política e emancipatória...

e aceitarem determinado modo de organização social como se este fosse a-histórico ou "natural" (algo que é assim porque é).

$\mathrm{O}$ entender a relação sociedade-natureza como uma relação ideal ou genérica naturaliza o que é social, no sentido de perda de historicidade, e estabelece de modo apriorístico o que é uma interação perfeita da humanidade na natureza. Essas concepçôes fragilizam a possibilidade de construção pelos educadores ambientais de um projeto societário alternativo e de uma prática educativa crítica, cidadã e popular. Numa perspectiva dialética, sociedade e natureza se fusionam pela práxis histórica (Schmidt, 1983), cuja unidade não pode ser confundida com a diluição de uma dimensão na outra. Cumpre ter presente que a humanidade não se constitui como unidade homogênea e que as condiçôes decorrentes da atuação humana no ambiente são definidas em função de cada modo de vida social, em interação com as condições ecológicas de sustentação. A visão que o marco teórico emancipatório em Educação Ambiental tem da humanidade é que esta é a unidade dialética com a natureza, em que os sujeitos são pensados concretamente e não abstratamente.

Em Educação Ambiental, as formulações sistêmicas geralmente estão associadas a premissas teóricas da visão holística, enquanto modo de pensar a totalidade e campo filosófico específico. Isso tem que ser ressaltado, pois não é raro encontrarmos seu uso como uma "idéia-força” imprecisa para denotar a preocupação com o todo. Suas formulações mais comuns no país, influenciadas pela teoria produzida por Fritjof Capra nos anos 1980 e 1990 (Capra, 1982, 1988, 1993), particularmente pelo que este chamou de "alfabetização ecológica", e por autores do Movimento Holístico Internacional (Crema, 1989 e Weil, 1990, 1994), apresentam igualmente alguns problemas que merecem atenção e reflexão crítica.

Os holísticos tendem a reificar, deificar ou sacralizar a natureza, retirando desta a dimensão humana em seu processo contínuo de transformação - ao estilo dos Deep Ecology. Buscam, dessa forma, a (re) ligação cósmica, capaz de encontrar uma autenticidade humana latente, como se esta tivesse sido perdida em algum tempo passado, numa atitude dogmática, de cunho religioso e de distanciamento indevido entre o natural e o social. Além disso, ao colocarem a "harmonização" com a natureza enquanto resultante de um movimento essencialmente espiritual, de transcendência pessoal, focalizam a educação como processo essencialmente individual, vivencial e comportamental, sem mediações sociais ou maiores preocupaçōes com as dimensões coletivas, sociopolíticas e 
societárias, posto que a condição para mudar o cenário contemporâneo passa a se situar nas pessoas e não no modo como socialmente nos organizamos, dissociando indivíduo-sociedade.

No dizer de Morin (2003), o princípio holista é baseado numa totalidade simplificante, pois seus adeptos tendem a pensar o todo como se este fosse sinônimo de tudo, simplificando as relaçôes e implicações mútuas e constitutivas entre partes e todo, suas irredutibilidades nas esferas da vida, e entre níveis diferenciados de totalidades. Numa visão complexa, pensada a partir de uma abordagem crítica e dialética de totalidade, inexiste um todo hipostasiado, descolado do movimento contínuo entre desordem/interações/ordem/organização. E nem é possível pensar o cosmos no qual existimos sem a nossa ação ativa. "Não é somente a humanidade que é um subproduto do devir cósmico, é também o cosmos que é um subproduto de um devir antropossocial.” (Morin, op. cit., p. 120).

Os holistas e sistêmicos funcionalistas ou organicistas minimizam os conflitos entre grupos e classes sociais em nome de uma cooperação e de um amor abstrato que pode, hipoteticamente, nos levar à harmonia com a natureza, como se existisse um estado absoluto e atemporal. Tendem, portanto, a desconsiderar o modo como tais valores se definem em sociedade e o movimento objetivo da realidade para além da ética e das idéias. Isso dificulta a construção de um "amor concreto" e de uma solidariedade que sejam decorrentes da explicitação das contradiçóes e estabelecimento do diálogo, considerando os diferentes "lugares" ocupados pelos agentes sociais numa sociedade historicamente definida. A Educação Ambiental holística se define como caminho para a superação por completo do conflito em nome da harmonia e do consenso, desconhecendo-se a dinâmica contraditória das sociedades humanas e históricas e ignorando-se o risco de se defender unilateralmente valores hegemônicos das classes dominantes como os mais corretos, "ecologicamente adequados", a serem, portanto, incorporados por aqueles que não possuem "consciência ambiental". Logo, o sentido de se construir coletivamente o que for melhor ambientalmente e para a vida, como resultante de um processo dialógico e democrático entre grupos sociais, seus saberes, culturas e necessidades distintas, fica prejudicado ou secundarizado.

Criam procedimentos de (re) ligação com a natureza, ampliando nossa condição de ser vivo, a partir de processos individualizados, psicológicos e místicos - é o "eu” em sintonia com o universo cósmico, sem mediações sociais. Isso acarreta a compreensão de que somos organismos 
Complexidade e dialética: contribuições à práxis política e emancipatória...

essencialmente biológicos e espirituais, não dando a devida relevância ao cultural, social e econômico - deixamos, portanto, de nos definirmos como seres multidimensionais e complexos. $\mathrm{O}$ mais grave, em termos políticos e de educação enquanto prática dialógica, é que tal prática holística promove um deslocamento da esfera pública de discussão e construção de projetos societários alternativos para a esfera privada e pessoal, subjetiva e sobrevivencial (Pelizzoli, 2002).

Enfatizam a "ecologização" da pedagogia, ao estilo da proposta de alfabetização ecológica de Capra (2003), priorizando as relações ecossistêmicas a partir de conceitos estruturantes da Ecologia vinculados a processos cooperativos, num enfoque ideologicamente biologizante. Tal ênfase dilui o entendimento do modo como as sociedades, os indivíduos e a cultura se definem mutuamente, e a capacidade de atuarmos politicamente. Mesmo quando partem de pedagogias construtivistas tendem a despolitizar a educação e a esvaziá-la como prática social. Associam a natureza à harmonia e dão destaque ao entendimento das relações ecológicas que são baseadas na cooperação, minimizando as que são fundadas na competição, quando ambas são indispensáveis para se entender o equilíbrio dinâmico que define a vida e, por analogia, as categorias que formam o todo social: conflito/consenso, cooperação/antagonismo, diálogo/dissenso. Por fim, não apresentam necessariamente como pressuposto pedagógico a construção participativa de temas geradores e o conhecimento coletivo e problematizador da realidade em que os grupos sociais se inserem. Tal posicionamento encontra-se em evidente contraposição a um dos princípios elementares da pedagogia freireana, uma vez que esta considera a problematização e a tomada de consciência coletiva da realidade vivida parte inerente ao processo educativo e de intervenção política com vistas à transformação social (Freire, 1988).

Após a análise teórica feita, chegamos às mesmas conclusões que Petraglia (2001), no que se refere ao sentido da educação para essas amplas visões sociais de mundo e tradições teórico-metodológicas em que se baseia a perspectiva ambientalista, em pesquisa realizada junto a intelectuais inseridos nas abordagens holística e complexa. O pensamento complexo e a tradição dialética, principalmente em sua formulação pedagógica freireana, enfatizam a educação enquanto processo permanente, cotidiano e coletivo pelo qual agimos e refletimos transformando a realidade de vida. Está focada na pedagogia do conflito, no princípio da incerteza, como forma de se estabelecer movimentos emancipatórios e políticos de transformação so- 
cial. A visão holística está centrada no indivíduo, no alcançar a condição de ser humano integral e harmônico, o que reforça os pressupostos de existência de finalidades previamente estabelecidas na natureza e de relaçóes ideais que fundamentam a pedagogia do consenso. Focaliza o ato educativo enquanto estímulo ao potencial transcendental que há em cada um de nós, com uma tendência a se aceitar a ordem social estabelecida como condição dada. $\mathrm{O}$ importante para essa vertente não é pensar processos educativos que associem mudança pessoal à mudança societária como pólos indissociáveis na requalificação de nossa inserção na natureza e na dialetização entre subjetividade-objetividade; mas sim pensar a transcendência integradora, a transformação da pessoa pela ampliação da consciência, como caminho único para se obter a uniāo com a natureza, subordinando a racionalidade à subjetividade. Em síntese, em termos das implicações sociopolíticas e de concepção do sujeito em sociedade e na natureza, "Entendemos que a complexidade se presta mais a uma educação emancipadora porque favorece a reflexão do cotidiano, o questionamento e a transformação social, enquanto a holística, ao propor o consenso de uma pedagogia que visa a harmonia e a unidade, acaba por estimular a domesticação e a acomodação" (Petraglia, op. cit., p. 144).

\section{Categorias estruturantes da Educação Ambiental}

Após as consideraçōes críticas sobre as implicaçōes da visão holística e sistêmica na Educação Ambiental, cabe reapresentar algumas categorias que definem uma abordagem complexa, dialética e emancipatória em educação. Falamos em reapresentar, uma vez que são categorias tradicionais e comuns para determinada orientação em educação que aqui são destacadas e afirmadas sob um olhar ambientalista de modo a esclarecer confusōes recorrentes no discurso de educadores ambientais. Com isso, não estamos querendo dizer que limites não possam ser apontados, pelo contrário, devemos fazê-lo até para avançarmos teoricamente, movimento que foi oportunamente realizado, por exemplo, pelo próprio autor ao explicitar contradições no modo de entendimento da natureza nas escolas marxistas do início do século XX (Loureiro, 2003a e 2004). Contudo, é preciso entender que, para uma educação concebida como meio de transformação social e cultural e ação política emancipatória, essa vertente apresenta inegável validade e conceitos vitais que evitam os problemas anteriormente indicados nas outras visões fundantes da Educação Ambiental. 
Complexidade e dialética: contribuições à práxis política e emancipatória...

A Educação Ambiental de conteúdo emancipatório e transformador é aquela em que a dialética forma e conteúdo se realiza de tal maneira que as alterações da atividade humana, vinculadas ao fazer educativo, impliquem mudanças individuais e coletivas. Em que a dimensão política da educação seja "a arte do compromisso e da intransigência" (Morin, 2002b, p. 43) compromisso com a transformação societária e intransigência na defesa dos valores, atitudes individuais e ações coletivas condizentes com a emancipação. Em que a dialética da vida seja um movimento ético e material, pois "trata-se ao mesmo tempo de mudar de vida e transformar o mundo, de revolucionar o indivíduo e de unir a humanidade" (Morin, 1999, p. 188).

Conteúdo emancipatório é entendido, nesse contexto, enquanto movimento de libertação consciente e de superação permanente das formas de alienação material e simbólica, coletiva e individual, existentes em cada fase historicamente definida (Adorno, 2000). Educar é emancipar a humanidade, criar estados de liberdade diante das condiçóes que nos colocamos no processo histórico e propiciar alternativas para irmos além de tais condiçôes. Não no sentido absoluto proposto pela Razão Iluminista e pela ciência moderna de matriz cartesiana e positivista. Estas acreditaram na prosperidade humana progressiva baseada no conhecimento total e no domínio da realidade pela racionalidade objetiva, em que, portanto, haveria um momento futuro para atingirmos a plenitude como ser.

A ação emancipatória é o meio reflexivo, crítico e autocrítico contínuo pelo qual podemos romper com a barbárie do padrão vigente de sociedade e de civilização, em um processo que parte do contexto societário em que nos movimentamos, do "lugar" ocupado por cada sujeito, estabelecendo experiências formativas, escolares ou não, em que a reflexão problematizadora da totalidade, apoiada numa ação política, propicia a construção de sua dinâmica. Emancipar não é estabelecer o caminho único para a salvação, mas sim a possibilidade de construirmos os caminhos que julgamos mais adequados à vida social e planetária, diante da compreensão que temos destes em cada cultura e momento histórico, produzindo patamares diferenciados de existência.

Nesse tipo de abordagem vinculada às pedagogias críticas inexistem, em resumo, relações entre seres humanos abstratos e natureza, mas relações entre sujeitos concretos, ou seja, indivíduos que existem em sociedade, e meio natural, formando uma totalidade que é a própria natureza - o que implica entender a natureza como uma categoria social e a sociedade como uma categoria natural (Marcuse, 1972; Schmidt, op. 
cit.). Assim, o intercâmbio mutuamente constituinte entre partes e todo não é apenas orgânico, mas socialmente ativo.

Para fins de sistematização dessa abordagem em Educação Ambiental, segue a descrição de três de suas categorias conceituais que substanciam o que é educar para a emancipação, visando à consolidação de padrôes de sociedade compatíveis com a justiça ambiental pensada e realizada de modo unitário com a justiça social.

\section{Dialética e transformação social}

Segundo Foulquié (1978), a origem da palavra dialética envolve discurso e razão, ou seja, se refere à discussão dialogada e racional que leva à compreensão. Logo, pode ser definida como a arte de, ao se dialogar, demonstrar argumentos e defender teses, evidenciando os conceitos envolvidos na discussão. A tradição dialética pode ser dividida em dois momentos: (1) a que vem dos antigos gregos até Hegel e que é concebida como lógica baseada no princípio da contradição; (2) a partir de Hegel, em que o contraditório passa a ser a norma do pensamento e das coisas, sendo este o princípio que gera o movimento entre conservação e superação, ordem e desordem, e permite o entendimento complexo da totalidade e a organização da vida. Segundo esse filósofo, dialética é a estrutura de pensamento e o método que permitem apreendermos a realidade como fundamentalmente contraditória e em constante transformação.

Marx, rompendo com o idealismo hegeliano e com a possibilidade aí inserida de se estabelecer sínteses e verdades absolutas, formula uma dialética baseada nos sujeitos concretos, nas relações sociais e nas condições históricas de vida - uma dialética que diz respeito, portanto, a como a vida é produzida, reproduzida e organizada (Naves, 2000). Para a dialética marxista as idéias são construídas na materialidade da vida e não o contrário, como no idealismo e nas teorias metafísicas, em que a vida é definida no plano ideal se exteriorizando no mundo material. Portanto, a matéria deixa de ser compreendida como coisas inertes e passíveis, e passa a ser definida como elementos em movimentos e relações, em que nenhum ser possui existência isoladamente (Engels, 1986). Em Marx, a dialética deixa de ser um método fundado para se obter verdades atemporais ou para se estabelecer um "jogo" entre argumentos e pensamentos e passa a definir as verdades como compreensôes datadas e situadas no processo de transformação da sociedade e de realização humana. 
Por ser uma dialética materialista-histórica, Marx enfatiza em sua obra o movimento de transformação social, a partir do entendimento do modo como produzimos e nos organizamos. Para o autor, o que importa não é apenas interpretar e especular, mas agir e transformar. A transformação da história humana se dá pelos próprios humanos, mas não seres abstratos e sim concretos, definidos pelas relações estabelecidas entre as esferas da vida social (política, cultural, filosófica, econômica etc.).

Partindo de Foulquié (op. cit.), e Marx e Engels (1986), num esforço de sistematização, certos princípios da dialética merecem destaque no escopo do presente texto:

- Existe interdependência ativa entre as partes do real.

- Tudo está em devir, em transformação permanente. Matéria e pensamento em repouso significam fim da vida.

- O movimento cria o novo, não pela evolução circular ou linear, mas pela revolução que implica mudança qualitativa e não apenas quantitativa.

- O real é intrinsecamente contraditório e é isso que garante o movimento da vida.

- Pelo caráter contraditório da história e do pensamento, as verdades são provisórias.

A dialética marxista se contrapõe às epistemologias metafísicas, à medida que estas colocam a essência como algo imutável, num descolamento entre idéia e matéria, em que a mudança das coisas torna-se um fenômeno superficial de algo mais denso e invariável. Para Konder (1997), esse tipo de lógica de pensamento foi e é dominante na história porque corresponde aos interesses das elites e classes dominantes, preocupadas em dar sentido universal e absoluto a seus valores e instituições que normatizam a vida em sociedade, inviabilizando a possibilidade racional de se buscarem mudanças sociais profundas. Afinal, se a essência é absoluta e os valores e o modo de organização social a expressam de forma completa, a sociedade não pode ser transformada, apenas ajustada e aprimorada.

No que se refere especificamente à discussão acerca da relação sociedade-natureza, é possível sintetizar alguns princípios da dialética por nós elencados em obras recentes (Loureiro, 2003a e 2004), a partir de Harvey (1996): 
- Elementos são demarcados por todos estruturados. A coisa ou o sistema devem ser entendidos e fundamentados nas relações que os constituem. Nada se define em si como parte isolada. Tudo é fluxo e processo relacional, singularidade e totalidade.

- Elemento e sistema são perpetuamente constituídos e reconstituídos por múltiplos processos.

- Partes e todos são mutuamente constitutivos de cada um, o que implica dizer muito mais do que a existência de retroalimentação entre eles.

- Há intercâmbio entre sujeito e objeto, causa e efeito, em conseqüência, os organismos são sujeitos e objetos da evolução e os indivíduos humanos, sujeitos e objetos do processo de mudança social.

- Mudança é a norma das coisas e sistemas e a história é feita pelo movimento permanente de transformação social, cultural, política e econômica, com profundas implicaçôes sobre o ambiente, o sentido de natureza e de realização da natureza humana.

Em termos das implicações políticas para a Educação Ambiental, adotar a perspectiva dialética significa reconhecer os sujeitos do processo educativo, ou seja, entender que os atores capazes de transformação social se definem vinculados ao modo de produção, à vida cotidiana particular e coletiva, ao Estado, e que estes devem participar com suas especificidades no trabalho pedagógico dialógico e comunicativo.

\section{Pensamento complexo, dialética e totalidade}

Na obra de Morin posterior à década de 1960, a complexidade se refere ao sentido de que a vida, em suas manifestações, se constitui por dimensões interconectas, definidas mutuamente nas relações estabelecidas, envolvendo ordem e desordem, erro e acerto, compromisso e intransigência, risco e certeza, numa autoprodução e reorganização permanente (Morin, 1999). O pensamento complexo busca fundamentalmente superar os paradigmas simplificadores que operam a disjunção ser humano/natureza ou que reduzem o ser humano à natureza de modo indistinto. Nessa perspectiva, a realização da natureza humana é aquilo que nos distingue como seres naturais das demais espécies: produzirmos 
Complexidade e dialética: contribuições à práxis política e emancipatória...

nossa história e os meios de vida, numa ação que pressupõe a capacidade de definir objetivos com consciência e o uso da cultura, da linguagem e da cooperação.

Posto que nada se define em si e de modo atemporal, mas em relações históricas e ecossistêmicas, e que somos seres específicos, sujeitos concretos, a tradição dialética marxista é, dentre as que se enquadram no pensamento complexo ambiental associado às pedagogias críticas, uma das que se propõe a teorizar e realizar a educação em bases contextualizadas, dando concretude às alternativas de superação ao modo como vivemos em sociedade. Como disse Marx (1999, p. 39), "o concreto é o concreto porque é a síntese de múltiplas determinações, isto é, unidade do diverso". Portanto, os indivíduos, os bens produzidos e os fatos tornam-se concretos à medida que conheçamos a totalidade que define cada indivíduo, fato ou bem produzido em relação à totalidade maior em que se inserem, num exercício complexo de totalização (Konder, 2002).

A dialética, como princípio metodológico, significa racionalmente compreender que o singular ganha sentido em suas relações (totalizaçóes) e que o todo é mais que a soma de singularidades e ao mesmo tempo diferente do singular, que tem suas propriedades próprias, num movimento de mútua constituição envolvendo não só o objetivo, o teórico e o coletivo, mas o subjetivo, o indivíduo, o espiritual e o intuitivo (Löwy, 1999). Como categoria metodológica, significa integrar teoria e prática, consciência e ser, matéria e idéia no processo histórico (Löwy, 2002). No pensamento dialético, o exercício totalizador busca a complexidade na ação que será sempre parcial, particular e historicamente condicionada. Segundo Konder (1997), qualquer objeto que possamos perceber ou criar é parte de um todo, por isso, a busca de soluções para os problemas depende de uma visão de conjunto, sempre provisória e que não esgota a realidade, mas é decisiva para que se possa situar e avaliar a dimensão de cada elemento dentro de uma estrutura significativa.

É importante lembrar que os conceitos de totalidade e complexidade para a educação não representam a negação da individualidade, mas sim do atomismo, posto que a individualidade concreta não é a que expressa o egoísmo e o isolamento do mundo (individualidade abstrata), mas a liberdade integrada no mundo (Löwy, 1989). Liberdade não é uma idéia transcendental, no sentido de se ir além das limitaçóes 
inerentes à natureza humana, que não são, portanto, limites castradores, mas sim condicionantes da nossa existência e meios de satisfação (comer, dormir, reproduzir, excretar etc.). Possui um caráter prático-transformador que se refere à superação pela práxis dos limites definidos na história (exclusão social e cultural, falta de acesso igualitário aos bens produzidos, despolitização, cidadania cerceada etc.).

Os sistemas filosóficos morais (teológicos, dualistas e idealistas), que colocam na essência humana valores vistos como atemporais e a-históricos (egoísmo, maldade, bondade, culpa, inocência etc.), querem libertar o ser humano de uma natureza entendida como "animal" ou "bruta" à qual são associados os valores "primitivos". Isso é, em última instância, a negação da natureza humana, pois estabelece a vida material como a limitação da liberdade que se dá em um plano espiritual, portador das virtudes, dicotomizado da vida. Nessa visão, quanto mais nos espiritualizamos (em sentido abstrato), mais nos afastamos da essência "selvagem" que é caracterizada por valores negativos. Ao se pensar de tal modo, a natureza torna-se um obstáculo e uma externalidade, e como o ser humano é natureza, a própria liberdade torna-se uma entidade fictícia ou, paradoxalmente, exclusivamente interna ao indivíduo concebido fora da história e da sociedade em seu processo de realização (Mészáros, 1981).

\section{Práxis e educação}

No dizer de Konder (1992), a práxis é a atividade concreta pela qual o sujeito se afirma no mundo, modificando a realidade objetiva e sendo modificado, não de modo espontâneo, mecânico e repetitivo, mas reflexivo, pelo autoquestionamento, remetendo a teoria à prática. Práxis "implica a ação e a reflexão dos homens sobre o mundo para transformálo" (Freire, 1988, p. 67). Refere-se à ação intersubjetiva, entre pessoas e dos cidadãos. É uma atividade relativa à liberdade e às escolhas conscientes, feitas pela interação dialógica e pelas mediações que estabelecemos com o outro, a sociedade e o mundo. É, portanto, um conceito central para a educação e, particularmente, para a Educação Ambiental, uma vez que conhecer, agir e se perceber no ambiente deixa de ser um ato teórico-cognitivo e torna-se um processo que se inicia nas impressóes genéricas e intuitivas e que vai se tornando complexo e concreto na práxis.

Esse é um aspecto decisivo para nos inserirmos numa visão emancipatória de educação. $\mathrm{Na}$ atividade humana coletiva nos educamos, 
com sujeitos localizados temporal e espacialmente. Ter clareza disso é o que nos leva a atuar em Educação Ambiental, mas não a partir do discurso genérico de que todos nós somos igualmente responsáveis e vítimas do processo de degradação ecossistêmica. Educar para transformar é agir em processos que se constituem dialogicamente e conflitivamente por atores sociais que possuem projetos distintos de sociedade, que se apropriam material e simbolicamente da natureza de modo desigual. Educar para emancipar é reconhecer os sujeitos sociais e trabalhar com estes em suas especificidades. A práxis educativa transformadora é, portanto, aquela que fornece ao processo educativo as condições para a ação modificadora e simultânea dos indivíduos e dos grupos sociais; que trabalha a partir da realidade cotidiana visando à superação das relações de dominação e de exclusão que caracterizam e definem a sociedade capitalista globalizada.

A educação não é a atividade de um sujeito pronto e constituído fora da transformação das condiçôes objetivas. Tem de ser "a atividade de um sujeito que, ao enfrentar o desafio de mudar o mundo, enfrenta também o desafio de promover sua própria transformação" (Konder, 1992, p. 117). A força educativa inovadora está na capacidade de trabalhar com a racionalidade e com as paixões, com a escolha e com a necessidade, com o fato objetivo e com as crenças, refletindo e agindo.

A educação é um dos meios humanos que garantem aos sujeitos, por maior que seja o estado de miséria material e espiritual e os limites de opções dados pelas condições de vida, o sentido de realização ao atuar na história modificando-a e sendo modificados no processo de construção de alternativas ao modo como nos organizamos e vivemos em sociedade.

\section{Considerações finais}

Consideramos relevante e urgente a demarcação dos distintos "campos ambientais em disputa" na conformação da Educação Ambiental, publicizando o debate e o diálogo entre tendências de modo a favorecer o entendimento das implicações práticas, pedagógicas e políticas no uso das tradiçôes que historicamente fundamentam a área. E absolutamente crucial, para a concretização de um novo patamar qualitativo da produção acadêmica em Educação Ambiental, que se aprofunde a reflexão teórica acerca daquilo que pode tornar possível ao educador discernir uma concepção ambientalista e educacional conservadora e tradicional de uma 
emancipatória e transformadora, e as variações e nuances que em ambas se inscrevem, problematizando-as, relacionando-as e superando-as permanentemente. E mais, entender como seus pressupostos são definidos no escopo das tradições sistêmicas, holísticas, complexas e dialéticas e quais são as implicações de cada uma no processo educativo e na explicitação de sua finalidade social. No discurso "harmonioso" feito em nome da salvação planetária, de defesa e afirmação de um "método unificador" das ciências, criase a ilusão de que todos os que fazem Educação Ambiental estão dentro de uma mesma orientação teórico-prática, como se as categorias conceituais que a sustentam - destacadamente participação, interdisciplinaridade, visão integradora do ambiente, respeito à diversidade biológica e cultural não permitissem diferentes apropriações e usos, dependendo da concepção teórica, do lugar social ocupado pelos sujeitos e da compreensão de sociedade da qual se parta.

A problematização feita em torno das formulações sistêmicas e holísticas não as desmerece em seus significados para a "questão ambiental", principalmente no repensar a vida, as relações ecossistêmicas, a integralidade do ser humano e o que seria uma ética planetária, mas procura evidenciar seus limites quando pensadas no contexto educacional e dos sentidos que a educação cumpre e assume na sociedade contemporânea. Com o contraponto feito, por fim, reiteramos a atualidade e centralidade da dialética marxista e da Teoria da Complexidade para a compreensão do modo como nos organizamos e historicamente nos constituímos enquanto seres biológicos e sociais. E, no escopo do que é significativo para a Educação Ambiental, destacamos a relevância destas para o entendimento das bases teórico-metodológicas fundantes das pedagogias críticas, promotoras de processos emancipatórios e da ação política em busca de patamares societários que permitam requalificar concretamente a inserção humana na natureza.

Recebido em março de 2004 e aprovado em julho de 2004.

Referências bibliográficas

ADORNO, T. W. Educação e emancipação. 2. ed. São Paulo: Paz \& Terra, 2000 .

BERTALANFFY, L. V. Teoria geral dos sistemas. Petrópolis: Vozes, 1977. 
Complexidade e dialética: contribuições à práxis política e emancipatória...

CAPRA, F. O ponto de mutação. São Paulo: Cultrix, 1982.

CAPRA, F. Sabedoria incomum. São Paulo: Cultrix, 1988.

CAPRA, F. O Tao da Física. 9. ed. São Paulo: Cultrix, 1993.

CAPRA, F. Alfabetização ecológica: o desafio para a educação do século 21. In: Trigueiro, A. (Coord.). Meio ambiente no século 21: 21 especialistas falam da questão ambiental. Rio de Janeiro: Sextante, 2003.

CREMA, R. Introdução à visão holística. São Paulo: Summus, 1989.

ENGELS, F. Anti-Dühring. In: Marx, K.; Engels, F. Obras fundamentales. México: Fondo de Cultura Económica, 1986.

FLORIANI, D.; KNECHTEL, M.R. Educação ambiental, epistemologia e metodologias. Curitiba: Vicentina, 2003.

FOULQUIÉ, P. A dialética. Lisboa: Europa-América, 1978.

FREIRE, P. Pedagogia do oprimido. 18. ed. Rio de Janeiro: Paz \& Terra, 1988.

HARVEY, D. Justice, nature and the geography of difference. Oxford: Blackwell, 1996.

KONDER, L. O futuro da filosofia da práxis. 2. ed. Rio de Janeiro: Paz \& Terra, 1992.

KONDER, L. O que é dialética. 28 ed. São Paulo: Brasiliense, 1997.

KONDER, L. A questão da ideologia. São Paulo: Cia das Letras, 2002.

LEFF, E. Epistemologia ambiental. São Paulo: Cortez, 2001.

LEFF, E. A complexidade ambiental. São Paulo: Cortez, 2003.

LIMA, G.F.C. Crise ambiental, educação e cidadania: os desafios da sustentabilidade emancipatória. In: Loureiro, C.F.B., LaYrargues, P.P.; Castro, R.S. (Org.). Educação ambiental: repensando o espaço da cidadania. São Paulo: Cortez, 2002.

LOUREIRO, C.F.B. O movimento ambientalista e o pensamento crítico: uma abordagem política. Rio de Janeiro: Quartet, 2003a. 
LOUREIRO, C.F.B. (Org.) Cidadania e meio ambiente. Salvador: Centro de Recursos Ambientais da Bahia, 2003b.

LOUREIRO, C.F.B. Trajetória e fundamentos da educação ambiental. São Paulo: Cortez, 2004.

LOUREIRO, C.F.B.; LAYRARGUES, P.P.; CASTRO, R.S. (Org.). Educação ambiental: repensando o espaço da cidadania. São Paulo: Cortez, 2002.

LÖWY, M. Método dialético e teoria política. 4. ed. Rio de Janeiro: Paz \& Terra, 1989.

LÖWY, M. Ideologias e ciências sociais. 13. ed. São Paulo: Cortez, 1999.

LÖWY, M. A Teoria da revolução no jovem Marx. Petrópolis: Vozes, 2002.

MARCUSE, H. Idéias sobre uma teoria crítica da sociedade. Rio de Janeiro: Zahar, 1972.

MARX, K. Para a crítica da economia política. São Paulo: Nova Cultural, 1999.

MARX, K.; ENGELS, F. Obras fundamentales. México: Fondo de Cultura Económica, 1986.

MÉSZÁROS, I. Marx: a teoria da alienação. Rio de Janeiro: Zahar, 1981.

MORIN, E. O paradigma perdido: a natureza humana. 6. ed. Lisboa: Europa-América, 1999.

MORIN, E. Os sete saberes necessários à educação do futuro. 6. ed. São Paulo: Cortez, 2002a.

MORIN, E. Em busca dos fundamentos perdidos. Porto Alegre: Sulina, 2002b.

MORIN, E. O método I: a natureza da natureza. 2. ed. Porto Alegre: Sulina, 2003.

NAVES, M. B. Marx: ciência e revolução. São Paulo: Moderna, 2000.

PELIZZOLI, M. L. Correntes da ética ambiental. Petrópolis: Vozes, 2002.

PETRAGLIA. I. Olhar sobre o olhar que olha. Petrópolis: Vozes, 2001. 
Complexidade e dialética: contribuições à práxis política e emancipatória...

SCHMIDT, A. El concepto de naturaleza en Marx. 4. ed. Madrid: Siglo XXI, 1983.

WEIL, P. Holística: uma nova visão e abordagem do real. São Paulo: Palas Athena, 1990.

WEIL, P. A nova ética. 2. ed. Rio de Janeiro: Rosa dos Tempos, 1994. 